DOI: $10.17805 / z p u .2018 .3 .15$

\title{
Стимулы к изучению русского языка у иранцев
}

\author{
М. ХАДЕМИ МОГАДДАМ \\ УНИВЕРСИТЕТ ТАРБИАТ МОДАРЕС, ИРАН
}

В настоящей статье перечисляются стимулы к изучению русского языка у иранцев. В число этих стимулов входят увлечение произведениями русской классической литературы; посещение туристических достопримечательностей России, желание знакомства с русской культурой, ее достижениями в разных областях, интерес к прибыльным инвестиционным возможностям России; знакомство с русским образом жизни, привычками и менталитетом, значение русского языка как глобального; интерес к истории России; образование в России. Изучение русского языка как обязательного второго иностранного (после английского) в школах Ирана, предложенное руководством Ирана, может представлять собой значительный шаг по распространению русского языка среди иранцев. Безусловно, вклад национальной культуры, основанной на этом языке, в современную мировую культуру также имеет большое значение. Значительную роль в распространении лингвистического и культурного влияния по-прежнему будут играть объемы торговли с промышленно развитыми и густонаселенными странами и масштабы международного туризма. Ключевые слова: иранцы; русский язык; Россия; Иран; международное сотрудничество 


\section{ВВЕАЕНИЕ}

Уиранцев есть свои веские причины для изучения русского языка. Возможно, им нравится звук русского акцента, они любуются русским балетом и восхищаются русской литературой, или они хотят путешествовать по этой огромной стране. Возможно, они планируют заниматься бизнесом в России или просто хотят посетить Москву как туристы. Но помимо этого, для иранцев знание русского языка открывает новые возможности для получения высшего образования, научной деятельности, делового общения и ведения бизнеса как в России, так и в других странах.

Поэтому статья посвящена анализу тех стимулов, которые есть у иранцев в изучении русского языка.

\section{РУССКАЯ КУАБТУРА}

По нашим наблюдениям, иранцы увлечены русской классической литературой и мечтают прочитать произведения русской классики в оригинале.

Такие талантливые русские писатели, как И. А. Бунин, А. П. Чехов, А. С. Пушкин, - авторы удивительно интересных литературных произведений. Известные труды $\Lambda$. Н. Толстого, Ф. М. Аостоевского и Н. В. Гоголя передают сущность русской души. Однако русская культура известна не только ее писателями. Многие гениальные музыканты и певцы, такие как Ойстрах, Шаляпин, Чайковский и десятки других, тоже родом из России. Слава русского балета и таких его звезд, как Анна Павлова, Михаил Барышников и Рудольф Нуреев, и сегодня не утихает. Российское культурное наследие широко известно во всем мире, и знание русского языка является обязательным для полного наслаждения им и понимания его.

Ничто так не сближает народы, как знание языков и культуры друг друга. Но достижений на этом поприще, подчеркнем, не так много. В России первая книга с персидского языка на русский была переведена еще в 1805 г. А на персидский язык с того времени было переведено 1048 произведений русской классической и современной литературы, из них 220 книг за последние пять лет. Русский язык в настоящее время изучается в десяти иранских университетах. Разумеется, российское государство должно помочь наладить обучение иранских школьников и студентов русскому языку, подготовить необходимые кадры преподавателей. Это огромный пласт работы.

Еще в 2009 г. в Москве был представлен учебник грамматики русского языка, разработанный специально для персоговорящих студентов и школьников российскими и иранскими лингвистами (Аитвинцев, 2018: Электронный ресурс). «Это первый учебник по русской грамматике для людей, говорящих на фарси, полностью учитывающий культурные особенности Ирана и сделанный на современном языковом материале, так прокомментировал в 2009 г. издание один из авторов - профессор кафедры русского языка МГУ Марина Сидорова. - Учебник полностью выверен для использования в исламских республиках. Пособие выдержано с точки зрения соблюдения даже самых деликатных моральных норм ислама» (Первый учебник ... , 2009: Электронный ресурс).

Пособие было разработано совместно с доцентом кафедры русского языка Тегеранского университета Сейедом Хасаном Захраи. Это первый учебник русского языка в Иране. В книге используются не только российские реалии, но и иранские: например, рядом с русским Новым годом соседствует Новруз. В тексте использованы впечатления российских путешественников, побывавших в Иране. Запланировано из- 
дание серии подобных учебных пособий по русскому языку. Но этого всего, повторяем, крайне недостаточно.

Мы не можем похвастаться многими переводами персидской литературы на русский язык. Это только поэзия великих персидских классиков Фирдоуси, Рудаки, Хайяма, Саади, Хафиза, Ажами в переводах А. Фета, В. Брюсова, М. Кузьмина, И. Сельвинского, В. Аержавина, А. Самойлова. Современная иранская литература русскому читателю известна гораздо меньше.

Иранцы много слышали о красоте и скромности русских женщин и хотят найти свою судьбу в России. Удивительные и загадочные русские женщины были музами у многих великих художников и писателей. Аюди рассказывали легенды о красоте русских женщин, а традиции и особенности русского воспитания формируют их благородный и скромный характер. Русские женщины придают большое значение семейным ценностям. Многие мужчины из разных стран мира мечтают о том, чтобы иметь жену из России. Поэтому, помимо изучения языка любви, было бы прекрасно овладеть родным языком своей будущей «второй половины».

\section{ЭКОНОМИКА РОССИИ}

Иранцы знают о прибыльных инвестиционных возможностях России и о создании компании в России.

Если они отправляются в командировку в Россию, то хотят быть готовыми общаться со своими российскими деловыми партнерами. Российские предприниматели хорошо разбираются в международной экономике и охотно устанавливают деловые отношения с зарубежными партнерами. Россия адекватно представлена на международной арене. Благодаря огромности страны и наличию природных ресурсов, российский рынок представляет большой интерес для иностранных бизнесменов. И серьезный бизнес требует серьезного подхода. Знание русского языка является обязательным условием для эффективной коммуникации с новыми деловыми партнерами.

Многие иранцы посещают Россию в разное время. Россия для нас - увлекательная и экзотическая страна. Она занимает обширную территорию, предлагающую множество возможностей насладиться курортными городами, испытать восторг от тайги с ее разнообразной дикой природой и неизведанными местами, посетить российский Аальний Восток - там, где восходит солнце, в то время как люди в западных частях страны еще крепко спят.

Иранцы знают, что жизнь в России сильно отличается. Их интересует все, что связано с русским образом жизни, привычками и менталитетом. Все - от воспитания детей до семейных ценностей, отношений с друзьями - имеет свой собственный вкус в России. Система образования (детские сады, школы), медицинские услуги и работа различных официальных организаций - все это в корне отличается от того, что характерно для Ирана. Но им будет намного легче утолить жажду знания всего русского, если понимать русский язык, говорить на нем.

Последние достижения в области технологий открыли безграничные возможности для общения. Расстояние больше не является барьером. Всего за несколько часов любой человек, имеющий компьютер и подключение к Интернету, может найти десятки новых друзей с похожими интересами со всего мира. Российские пользователи Интернета активно изучают виртуальное пространство - запускают личные блоги, публикуют обновления в социальных сетях. В русских школах изучение английского языка начинается с начальных классов, поэтому большинство россиян могут понять 
несколько английских фраз и выразить простые идеи на английском языке. Так почему бы не научиться немного русскому?

Русский язык является наиболее распространенным среди славянских языков. Иранцы обязательно должны это узнать - в мире насчитывается около 300 миллионов носителей русского языка. Русский стал одним из языков мирового общения еще в XX в. Сегодня в мире насчитывается менее десяти языков международного общения. Это означает, что русский язык - точно так же как английский, французский или немецкий - используется для общения очень большого числа людей по всему миру. Кроме того, русский язык является одним из официальных языков ООН. Примерно из 300 миллионов человек в мире, которые знают русский язык, 160 миллионов человек считают его родным. Русский язык считается пятым по распространенности в мире языком.

Иранцев серьезно интересует история России. Аля работы с архивными документами требуется знание русского языка.

Историческое прошлое России имеет большое значение для понимания мировой истории. Фактически Россия играла решающую роль в развитии мира в течение последних нескольких столетий. Недавно российские власти открыли доступ к разнообразным архивам, хранящим много ценных документов. Эти материалы позволяют исследователям заглядывать в прошлое и понимать причины многих глобальных событий. Однако изучение этих документов возможно только в том случае, если вы понимаете русский язык.

\section{ОБРАЗОВАНИЕ В РОССИИ}

Многие иранцы планируют продолжать образование в университетах России, особенно в магистратуре и аспирантуре. Россия является одной из передовых стран в области фундаментальных наук, математики, физики, химии, аэрокосмической инженерии, нанотехнологии, искусства, музыки и т. А. Относительно близкое расстояние и транспортные связи между Тегераном и Москвой, хорошие отношения между двумя странами, гостеприимство русского народа, прекрасная архитектура Москвы все эти факторы привлекают многих иранцев ежегодно в Россию, чтобы продолжать образование в Москве, Санкт-Петербурге и в других городах.

Выдвижение русского языка в семью мировых языков началось с Великой Октябрьской социалистической революции. В связи с ростом международного авторитета Советского Союза (особенно после Второй мировой войны), теми огромными достижениями, которыми ознаменовался труд советского народа в области строительства социализма, в развитии науки и техники, литературы и просвещения, русский язык в настоящее время превратился в один из мировых языков.

В настоящее время в университетах Ирана преподают русский язык и литературу. Преподавание русского языка осуществляется в Тегеранском университете более 70 лет. Тегеранский университет, называемый «матерью всех университетов Ирана», был основан в 1934 г. Кафедра русского языка факультета иностранных языков Тегеранского университета приступила к своей работе одновременно с открытием университета. На этой кафедре студенты получают степень бакалавра по двум направлениям: «Русский язык и литература» и «Подготовка переводчика русского языка» (Ханджани, 2014: Электронный ресурс).

Каждый человек должен стремиться к развитию и совершенствованию. Мудрый человек всегда будет интересоваться новыми открытиями и освоением новых зна- 
ний. Считается, что чем больше языков человек знает, тем более умным и образованным он становится. Изучение русского языка должно быть вдвойне интересно, потому что многие носители персидского языка считают русский акцент необычным и красивым.

Мудрое иранское руководство сделало значительные шаги в сближение стран. Еще два года назад в иранских школах было введено изучение русского языка в качестве обязательного второго иностранного (после английского). Аетям с 6-го класса предлагают на выбор русский, немецкий, итальянский, испанский или французский. Поразительно, но, по данным Министерства образования Ирана, русский в этой пятерке становится лидером по популярности. Причины такого предпочтения легко объяснимы: Иран и Россия как соседи связаны многовековыми традициями отношений.

Включение русского языка в школьную программу - дружеский и одновременно прагматичный шаг Ирана в сторону России. Он напрямую связан с оживившимися надеждами на многостороннее развитие отношений двух стран, на реализацию совместных торгово-экономических, научно-технических и гуманитарных проектов.

Как говорится, шаг теперь за великой Россией. Почему в России изучают многие восточные языки в средних школах, включая китайский, хинди, иврит, а фарси - нет? Это недальновидность или политика? В России, кстати, столько мусульманских школ, как ни в одной стране мира со смешанным населением, в таких республиках, как Башкирия, Татарстан.

Конечно, не только число носителей языка определяет роль языка в мировой цивилизации. Значительную роль играет уровень экономического и научно-технического развития стран, использующих этот язык; большое значение имеют также сферы, в которых его использование является приоритетом.

Сохранит ли русский язык свое место среди десяти ведущих языков мира в обозримом будущем? Это зависит прежде всего от того, сможет ли российская экономика в ближайшем будущем перейти к производству знаний и экспорта образовательных и научно-технических услуг, которые сегодня пользуются наибольшим спросом среди всех продуктов человеческой деятельности. Приоритетное развитие сферы образования и науки и внедрение технологий, основанных на них в промышленном секторе экономики, - единственный путь от сползания на обочину научно-технического прогресса.

Вопрос в том, в какой роли Россия и русский язык будут полезными, интересными и привлекательными для представителей разных стран и народов. Поставка углеводородного сырья для промышленно развитых стран и производство вооружений для азиатских и некоторых арабских и латиноамериканских государств, которыми в настоящее время занимается Российская Федерация, не могут объективно ускорить укрепление позиций русского языка в мире.

\section{ЗАКАЮЧЕНИЕ}

Русский язык обладает большим потенциалом для сближения народов Ирана и России. Тем не менее это единственный язык среди 10-12 ведущих языков мира, который стабильно теряет свои позиции во всех основных регионах за последние 20 лет. Если русское государство не будет принимать меры по әффективной поддержке русского языка и культуры в России и за рубежом в ближайшем будущем, эта негативная тенденция сохранится. 
СПИСОК АИТЕРАТУРЫ

Иитвинцев, Г. М. (2018) Россия - Иран: Вопросы культурного взаимодействия [Электронный ресурс] // РИА Иран.Ру. URL: http:// http://www.iran.ru/news/analytics/92642/Rossiya_ Iran_Voprosy_kulturnogo_vzaimodeystviya (дата обращения: 12.03.2018).

Первый учебник русского языка для иранцев представлен в Москве (2009) [Электронный ресурс]// РИА Новости. 25 марта. URL: https://ria.ru/society/20090325/165996399.html (дата обращения: 12.03.2018).

Ханджани, $\Lambda$. (2014) Русский язык в Иране: история, современное состояние, перспективы развития [Электронный ресурс]// Молодой ученый. № 12. C. 438-441. URL: https://moluch.ru/ archive/71/12206 (дата обращения: 12.03.2018).

Aата поступления: 15.03 .2018 2.

\section{STIMULI TO LEANING THE RUSSIAN LANGUAGE BY THE IRANIANS \\ M. KHADEMI MOGHADDAM \\ TARBIAT MODARES UNIVERSITY, IRAN}

The article lists the incentives for Iranian people to learn the Russian language. These stimuli include a fascination for the works of Russian classical literature; visiting Russian tourist attractions; a desire to get acquainted with Russian culture and its achievements in various fields; an interest in Russia's profitable investment opportunities; acquaintance with the Russian way of life, habits and mentality; the significance of Russian as a global language; an interest in Russian history; education in Russia. Learning Russian as a compulsory second foreign language (after English) at schools of Iran, proposed by the leaders of Iran, can represent a significant step towards the diffusion of the Russian language among the Iranians. There is no doubt that the contribution to the modern world culture made by the national culture based on this language is also of great importance. Large volumes of trade with industrially developed and densely populated countries and the scale of international tourism will continue to play a significant role in spreading linguistic and cultural influence.

Keywords: Iranians; Russian language; Russia; Iran; international cooperation

\section{REFERENCES}

Litvincev, G. M. (2018) Rossiya - Iran: Voprosy kul'turnogo vzaimodejstviya. RIA Iran.Ru [online] Available at: http:// http://www.iran.ru/news/analytics/92642/Rossiya_Iran_Voprosy_kulturnogo_vzaimodeystviya (access date: 12.03.2018). (In Russ.).

Pervyj uchebnik russkogo yazyka dlya irancev predstavlen v Moskve (2009). RIA Novosti, 25 Mars [online] Available at: https://ria.ru/society/20090325/165996399.html (access date: 12.03.2018). (In Russ.).

Handzhani, L. (2014) Russkij yazyk v Irane: istoriya, sovremennoe sostoyanie, perspektivy razvitiya. Molodoi uchenyi, no. 12, pp. 438-441. URL: https://moluch.ru/archive/71/12206 (access date: 12.03.2018). (In Russ.).

Submission date: 15.03 .208$.

Хадеми Могаддам Мохсен - кандидат филологических наук, Университет Тарбиат Модарес. Адрес: Иран, г. Махмудабад, ул. Имам Хомейни, пер. Насим 31, д. 47. Тел.: (+98) 937-3628712. Эл. aspec: Mohsenkhademi.63@gmail.com

Khademi Moghaddam Mokhsen, Candidate of Philology, Tarbiat Modares University. Postal address: 47, Imam Khomeini St., Nasim Lane 31, Mahmudabad, Iran. Tel.: (+98) 937-3628712. E-mail: Mohsenkhademi.63@gmail.com 